\title{
Septal Modulation of Excitatory Transmission in Hippocampus
}

\author{
Laura Lee Colgin, ${ }^{1}$ Enikö A. Kramár, ${ }^{1}$ Christine M. Gall, ${ }^{2}$ and Gary Lynch ${ }^{1}$ \\ ${ }^{1}$ Department of Psychiatry and Human Behavior and ${ }^{2}$ Department of Anatomy and Neurobiology, University of California, Irvine, \\ California 92612
}

Submitted 19 March 2003; accepted in final form 1 July 2003

Colgin, Laura Lee, Enikö A. Kramár, Christine M. Gall, and Gary Lynch. Septal modulation of excitatory transmission in hippocampus. $J$ Neurophysiol 90: 2358-2366, 2003. First published July 2, 2003; 10.1152/jn.00262.2003. Application of the acetylcholinesterase inhibitor physostigmine to conventional hippocampal slices caused a significant reduction of field excitatory postsynaptic potentials (EPSPs) elicited by single pulse stimulation to the medial perforant path. Similar but smaller effects were obtained in the lateral perforant path and other excitatory pathways within hippocampus. The reductions were blocked by atropine, were not accompanied by evident changes in the EPSP waveform, and were eliminated by lesions to the cholinergic septo-hippocampal projections. Antidromic responses to mossy fiber stimulation, recorded in stratum granulosum, were not affected by the drug. However, paired-pulse facilitation was reliably increased, indicating that the depressed synaptic responses were secondary to reductions in transmitter release. The absence of cholinergic axo-axonic connections in the molecular layer suggests that physostigmine reduces presynaptic release by increasing retrograde signaling from the granule cells. In accord with this, an antagonist of the CB1 cannabinoid receptor eliminated the effects of physostigmine on synaptic responses, while an antagonist of the presynaptically located $\mathrm{m} 2$ muscarinic acetylcholine receptor did not. This is in contrast to previously reported effects involving application of cholinergic agonists, in which presynaptic inhibition likely results from direct activation of presynaptically located muscarinic receptors. In summary, it is proposed that the cholinergic inputs from the septum to the middle molecular layer modulate, via endocannabinoid release, the potency of the primary excitatory afferent of hippocampus.

\section{N T R O D U C T I O N}

While the great majority of hippocampal afferents arise in the entorhinal cortex (Blackstad 1958; Cajal 1955; HjorthSimonsen 1972; Hjorth-Simonsen and Jeune 1972; Nafstad 1967; Raisman et al. 1965), the medial septum and diagonal bands (nDBB) are also important sources of input (Amaral and Kurz 1985; Lynch et al. 1977; Mosko et al. 1973; Raisman et al. 1965). Despite their relative sparseness, it has been known for some time that the latter projections play a critical role in the production of various rhythms in hippocampus (Gogolak et al. 1968; Petsche et al. 1962; Stewart and Fox 1989). This regulation in part is mediated by muscarinic acetylcholine receptors (Kramis et al. 1975; Buzsaki et al. 1983), an observation that accords with results showing the septum/nDBB is the primary source of cholinergic input to hippocampus (Lewis et al. 1967; Lynch et al.

Address for reprint requests and other correspondence: L. L. Colgin, Dept. of Psychiatry and Human Behavior, Univ. of California, Irvine, 101 Theory, Suite 250, Irvine, CA 92612 (E-mail: lcolgin@uci.edu).
1977; Mellgren and Srebro 1973; Mosko et al. 1973; StormMathisen 1977). The hippocampus thus appears to process a massive glutamatergic input from the cortex using synchronizing rhythms that depend on a much smaller collection of afferents releasing a different transmitter.

Cholinergic stimulation reduces the size of synaptic responses in glutamatergic projections in hippocampus, including the perforant path (Foster and Deadwyler 1992; Kahle and Cotman 1989; Konopacki et al. 1987; Yamamoto and Kawai 1967), CA3 associational fibers (Hasselmo et al. 1995), and Schaffer collaterals (Hasselmo and Fehlau 2001; Qian and Saggau 1997). Pyramidal neurons are partially depolarized by cholinergic stimulation (Benson et al. 1988; Madison et al. 1987; Nakajima et al. 1986), raising the possibility that reductions in the size of excitatory postsynaptic potentials (EPSPs) are due to a loss of driving force. However, this hypothesis predicts that acetylcholine (ACh) will similarly reduce responses produced by ionophoresis of glutamate, which is not the case (Valentino and Dingledine 1981). Cholinergic activation also increases excitability in a group of GABAergic interneurons located in stratum oriens (Behrends and ten Bruggencate 1993; Pitler and Alger 1992a), so it is possible that cholinergic suppression of glutamatergic pathways may involve increased hyperpolarization. This mechanism is unlikely, however, given that ACh sustains its suppressive effect on perforant path EPSPs in Cl-deficient medium (Yamamoto and Kawai 1967). By exclusion, then, decreases in response size are probably due to reduced neurotransmitter release, an idea recently supported by evidence that cholinergic agonists inhibit presynaptic calcium currents (Qian and Saggau 1997).

Few experiments have examined possible interactions between cholinergic septal afferents and glutamatergic pathways in hippocampus. The aforementioned studies of cholinergic effects used ACh and/or its agonists, and it is not clear how the results are related to release from septal terminals. The present study addresses this issue by testing the effects of the AChE inhibitor physostigmine on EPSPs in various hippocampal pathways in slices from both normal rats and animals in which the septal inputs to hippocampus were removed. The results indicate that enhanced cholinergic transmission affects excitatory transmission by depressing glutamate release and further suggest that the effect is mediated by cannabinoid receptors.

\footnotetext{
The costs of publication of this article were defrayed in part by the payment of page charges. The article must therefore be hereby marked "advertisement" in accordance with 18 U.S.C. Section 1734 solely to indicate this fact.
} 


\section{METHODS}

\section{Slice preparation}

Experiments were conducted using hippocampal slices prepared from male Sprague-Dawley rats (approximately $5 \mathrm{wk}$ of age) following a protocol approved by the University of California Institutional Animal Care and Use Committee and in accordance with guidelines set forth by the National Institutes of Health. Following halothane anesthesia, rats were decapitated, and the brain was quickly removed and placed in ice-cold, oxygenated dissection medium containing (in mM) $124 \mathrm{NaCl}, 3 \mathrm{KCl}, 1.25 \mathrm{KH}_{2} \mathrm{PO}_{4}, 5 \mathrm{MgSO}_{4}, 3.4 \mathrm{CaCl}_{2} \times 2 \mathrm{H}_{2} \mathrm{O}$, $26 \mathrm{NaHCO}_{3}$, and 10 glucose. Transverse hippocampal slices $(375 \mu \mathrm{m}$ thick) through the mid- to ventral portion of the septo-temporal axis of the hippocampus were prepared using a McIlwain tissue chopper or Leica vibrating tissue slicer (Model:VT1000S) before being transferred to an interface recording chamber containing medium of the following composition (in $\mathrm{mM}$ ): $124 \mathrm{NaCl}, 3 \mathrm{KCl}, 1.25 \mathrm{KH}_{2} \mathrm{PO}_{4}, 2.5$ $\mathrm{MgSO}_{4}, 3.4 \mathrm{CaCl}_{2}, 26 \mathrm{NaHCO}_{3}$, and 10 glucose. Slices were continuously perfused with this solution at a rate of $75 \mathrm{ml} / \mathrm{h}$ and maintained at $31 \pm 1{ }^{\circ} \mathrm{C}$, while warm, humidified $95 \% \mathrm{O}_{2}-5 \% \mathrm{CO}_{2}$ was blown from above. Recordings began following $\geq 1 \mathrm{~h}$ of incubation.

\section{Stimulation and recording}

Lateral and medial perforant path (LPP and MPP) fibers entering the hippocampal formation were stimulated $(0.05 \mathrm{~Hz})$ with twisted nichrome wire $(65 \mu \mathrm{m})$ positioned in the outer- and middle-third of the dentate gyrus molecular layer, respectively. A single glass pipette filled with $0.15 \mathrm{M} \mathrm{NaCl}$, yielding a resistance of 3-5 M $\Omega$, was used to record extracellular field EPSPs (fEPSPs) in the same strata of the molecular layer as the stimulated LPP or MPP projections. Since the LPP and MPP activate a relatively narrow beam of fibers, the final determination of whether the lateral or medial perforant path was stimulated was confirmed by paired-pulse stimulation. The delivery of two stimuli in close succession (50-ms interstimulus interval) elicited paired-pulse depression in the MPP, whereas LPP stimulation elicited paired-pulse facilitation, as reported previously (McNaughton 1980).

Stable fEPSPs were obtained by adjusting stimulation intensity to elicit a baseline response that was approximately $1.5-2.0 \mathrm{mV}$ in size and $<50 \%$ of the maximal monophasic response. Evoked responses were recorded using a differential AC amplifier (Model 1700, A-M Systems, Carlsborg, WA) and digitized at $10 \mathrm{KHz}$ using NacGather software (Theta Burst, Irvine, CA). The sample size for all experiments represents the number of animals used.

\section{Drug application}

All compounds were obtained from Sigma (St. Louis, MO), with the exception of AM251, which was obtained from Tocris (Ellisville, MO). The acetycholinesterase inhibitor, eserine (physostigmine), was prepared on the day of the experiment as a stock solution $(10 \mathrm{mM})$ in double distilled $\mathrm{H}_{2} \mathrm{O}$ and diluted to a working concentration (1-5 $\left.\mu \mathrm{M}\right)$ with artificial cerebro-spinal fluid (ACSF). The CB1 cannabinoid antagonist, AM251, was dissolved in a stock solution of $100 \%$ dimethylsulfoxide (DMSO) and stored at $-20^{\circ} \mathrm{C}$ until the day of the experiment. Prior to application, the AM251 stock solution $(10 \mathrm{mM})$ was diluted with ACSF to a final working concentration $(4-8 \mu \mathrm{M})$ containing $<0.1 \%$ DMS0. Atropine solutions were prepared from salt on the day of the experiment.

\section{Fornix/fimbria lesion and acetylcholinesterase histochemistry}

For ablation of cholinergic septal afferents, 4- to 5-wk-old male Sprague-Dawley rats were anesthetized with ketamine and xylazine (50 and $10 \mathrm{mg} / \mathrm{kg}$, respectively; ip), and a window of bone overlying the septal pole of hippocampus was removed. A drawn glass aspiration pipette was used to remove the neocortex overlying the anterior tip of hippocampus and then to ablate the fimbria/fornix anterior and medial to this. There was some variable damage to the septal nuclei. At 5-10 days postlesion, the rats were killed and the hippocampus ipsilateral to the lesion was used for preparation of acute hippocampal slices and electrophysiological recordings, carried out as described above. The slices were then fixed in $4 \%$ paraformaldehyde $(0.5-2$ days, $4^{\circ} \mathrm{C}$ ), sectioned at $30 \mu \mathrm{m}$ parallel to the surface of the slice, and processed free floating for histochemical localization of actylcholinesterase using a modification of methods of Koelle and Friedenwald (1949) (Broide et al. 1996; Mosko et al. 1973). Sections were incubated in a tetraisopropylpyrophosphoramide/acetylthiocholide iodide solution overnight at room temperature and developed in $1 \%$ ammonium sulfide for $45 \mathrm{~s}$.

\section{Data analysis}

Student's $t$-tests were carried out to determine statistical significance of the results. Data are presented as means $\pm \mathrm{SE}$.

\section{RES U L T S}

Figure 1 illustrates the effects of $5 \mu \mathrm{M}$ physostigmine on fEPSPs recorded in the molecular layer of the dentate gyrus in response to stimulation of the lateral or medial perforant path. Responses to paired stimulation pulses were used to distinguish between medial and lateral perforant paths; representative examples are shown in Fig. $1, A$ and $B$ (inset). The AChE inhibitor reduced the size of the responses beginning 10-15 min after the start of infusion, with maximum effects appearing over the following $30 \mathrm{~min}$. In the apparatus used in the present experiments, compounds added to the infusion lines require about $5 \mathrm{~min}$ to reach the slices and an additional several minutes to reach their maximum bath concentration. The field EPSP depression was modest in size, did not appear to be accompanied by distortions of waveform (Fig. $1 C$ ), and was reliably larger for the medial than for the lateral perforant path $(-26 \pm 4 \%$ vs. $-9 \pm 2 \%$, at $40-50 \mathrm{~min}$ after the start of infusion; $P<0.004$, 2-tailed $t$-test; Fig. $1, A$ and $B)$. The threshold physostigmine concentration for reliable reductions was about $1 \mu \mathrm{M}$ (data not shown), and the effects of physostigmine were blocked by atropine at $10 \mu \mathrm{M}$ (Fig. $1 D$ ).

The above effects were not restricted to the dentate gyrus. Physostigmine caused reliable depressions in fEPSPs elicited by stimulation of Schaffer-commissural afferents to field CA1 (Fig. 2A), consistent with in vitro reports involving application of ACh (Hasselmo and Fehlau 2001). There were no reliable alterations in mossy fiber responses (Fig. 2B), which is not unexpected given a recent report indicating that the agonist muscarine does not directly affect mossy fiber transmission (Vogt and Regehr 2001). It appears then that physostigmine's effects, although especially large in the medial perforant path, are not restricted to the dentate gyrus.

Figure 3 illustrates the results obtained in hippocampal slices prepared from rats in which the septo-hippocampal fibers had been severed by ablation of the fimbria/fornix at the level of the hippocampal commissure. Surgery was carried out $\geq 5$ days prior to physiological recording to allow the septal projections to degenerate; the delay was sufficient to cause the loss of virtually all AChE staining at the time of testing (Fig. 3B). fEPSPs appeared normal in the denervated slices, and as shown in Fig. 3, $C$ and $D$, were unaffected by physostigmine.

The low concentrations of physostigmine used to depress perforant path responses did not appear to affect the excitabil- 
A

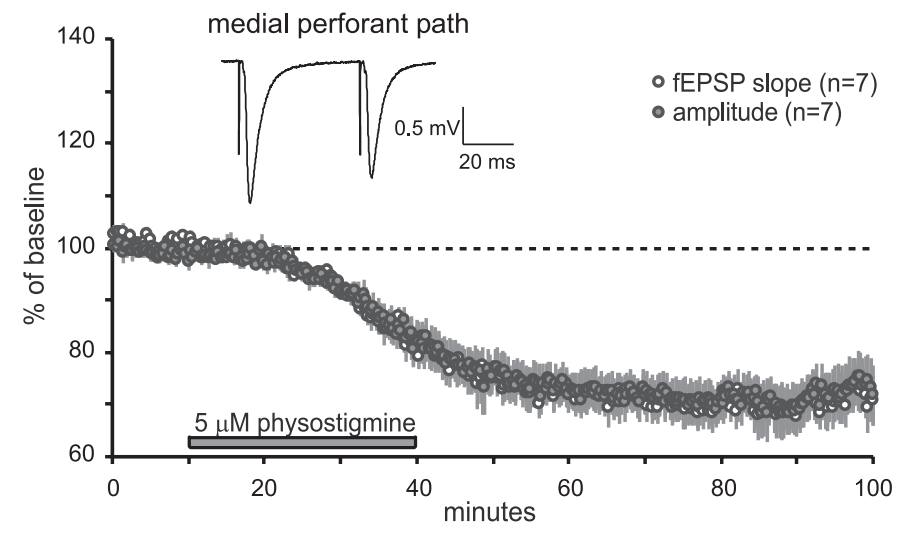

B

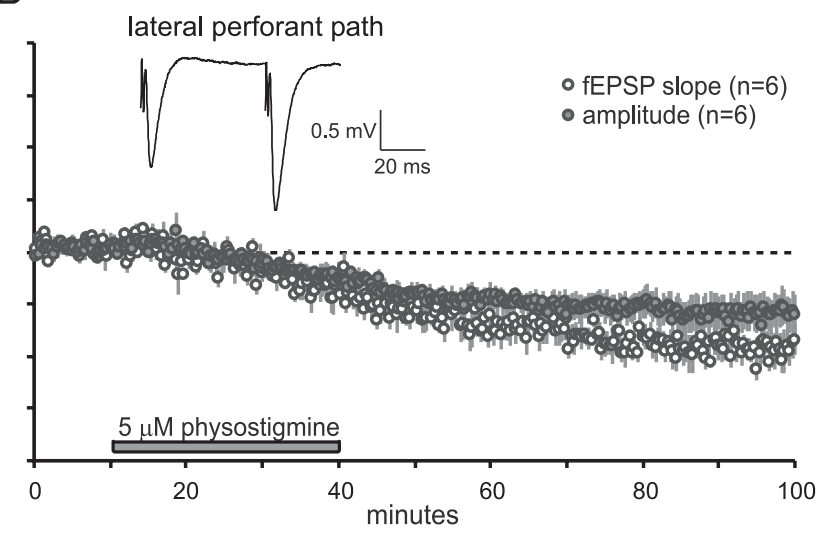

C

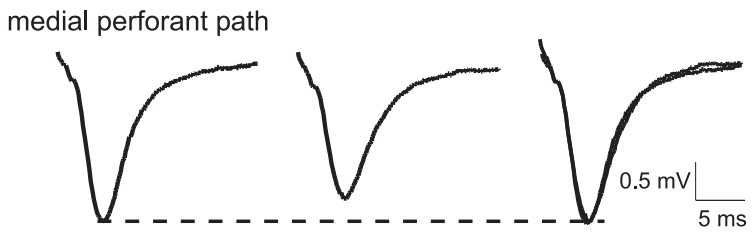

lateral perforant path
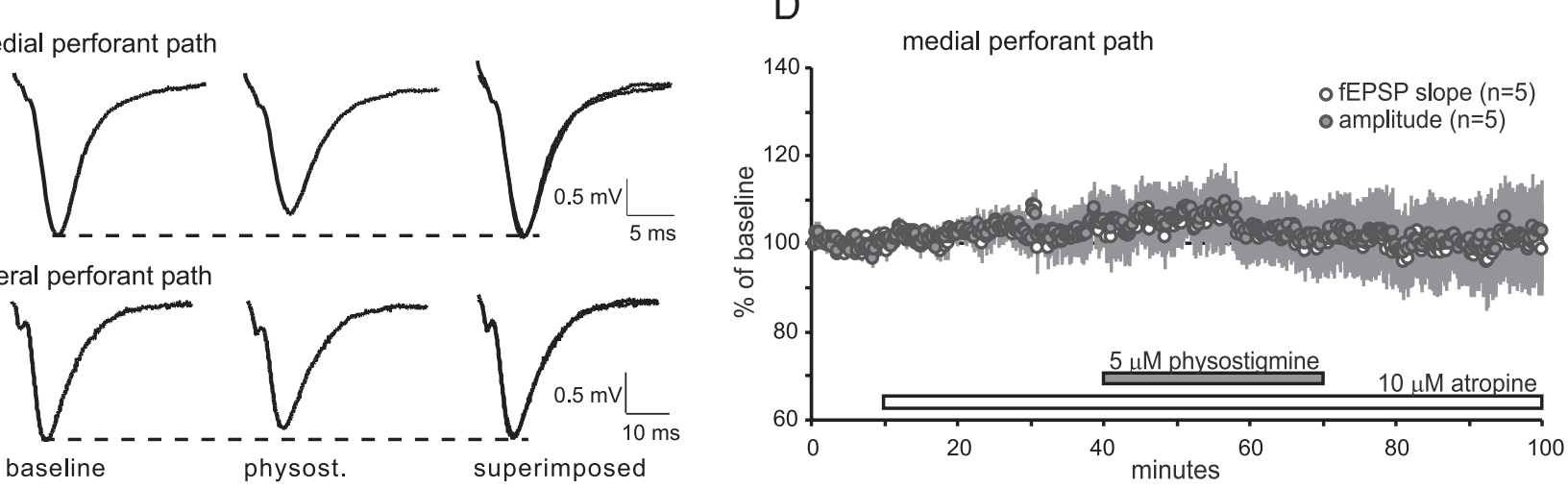

FIG. 1. Effects of physostigmine on the size of perforant path responses. Single pulse stimulation was applied to the perforant path near the hippocampal fissure and recordings collected from the middle (medial perforant path) or outer (lateral perforant path) molecular layer of the inner leaf of the dentate gyrus. Paired-pulse facilitation and depression were used to confirm that responses were generated by the lateral or medial perforant paths, respectively ( $A$ and $B$, inset). Physostigmine (infused for the period denoted by bar) caused a large depression of medial perforant path responses $(A)$ and a reliable but smaller decrease in the lateral path response $(B)$. Normalizing responses recorded during drug infusion to the amplitude of the predrug response indicated that physostigmine did not alter the waveform of the field excitatory postsynaptic potential (EPSP) $(C)$. The muscarinic antagonist atropine completely blocked the effects of physostigmine on EPSPS $(D)$.

ity of the postsynaptic granule cells. The amplitude of the antidromic population spike elicited by stimulation of the mossy fibers was not measurably changed (Fig. 4A), as would have occurred if the drug affected the spiking probabilities of the granule cells. Verification that the responses recorded were indeed activated antidromically was provided by the observation that they reliably followed high-frequency trains of stimulation (Fig. 4B).

The absence of evident postsynaptic changes or alterations in the shape of the fEPSP waveform points to the conclusion that physostigmine reduces synaptic responses by depressing release. Paired-pulse facilitation, a simple and sensitive measure of changes in release probability, was used to test this hypothesis (Fig. 5). Mean paired-pulse facilitation of lateral perforant path responses was increased by low $(1 \mu \mathrm{M})$ concentrations of physostigmine, but the effects were variable and did not reach statistical significance. A 5- $\mu \mathrm{M}$ concentration of the drug reliably enhanced paired-pulse facilitation in the lateral perforant path with the same infusion time-course over which fEPSPs were reduced. Mean facilitation of the response slope was $29 \pm 3 \%$ before physostigmine $(5 \mu \mathrm{M})$ and $46 \pm 5 \%$ at the end of infusion $(P<0.02)$; comparable values for response amplitude were $30 \pm 3 \%$ and $41 \pm 2 \%(P<0.009)$.

Extensive electron microscopic analyses have determined that axo-axonic contacts are rare in the molecular layer of the dentate gyrus, while cholinergic (i.e., choline acetyltransferase and/or AChE positive) terminals in that region are reported to form dendritic contacts (Clarke 1985; Cotman et al. 1973; Frotscher and Leranth 1985). Any direct effect of ACh released from septal projections on perforant path terminals would therefore have to be mediated by diffusion. An alternative possibility is suggested by recent work indicating that endogenous cannabinoids from postsynaptic neurons can suppress release from presynaptic terminals (Hajos and Freund 2002; Hajos et al. 2001; Maejima et al. 2001; Ohno-Shosaku et al. 2001; Wilson and Nicoll 2001), including release from glutamatergic synapses (Ameri et al. 1999; Gerdeman and Lovinger 2001; Hajos et al. 2001; Shen et al. 1996; Sullivan 1999). Moreover, there is good evidence that cholinergic stimulation in the hippocampus initiates endocannabinoid release (Kim et al. 2002). The selective CB1 antagonist AM251 was used to test if cannabinoid receptors mediate the effects of physostigmine on perforant path responses in the dentate gyrus. As shown in Fig. 6, $A$ and $B$, physostigmine had no effect on medial or lateral perforant path fEPSPs in slices pretreated with a cannabinoid receptor antagonist. Because AM251 is dissolved in DMSO, control slices were treated with DMSO at the same concentration; in these cases, physostigmine produced 
A
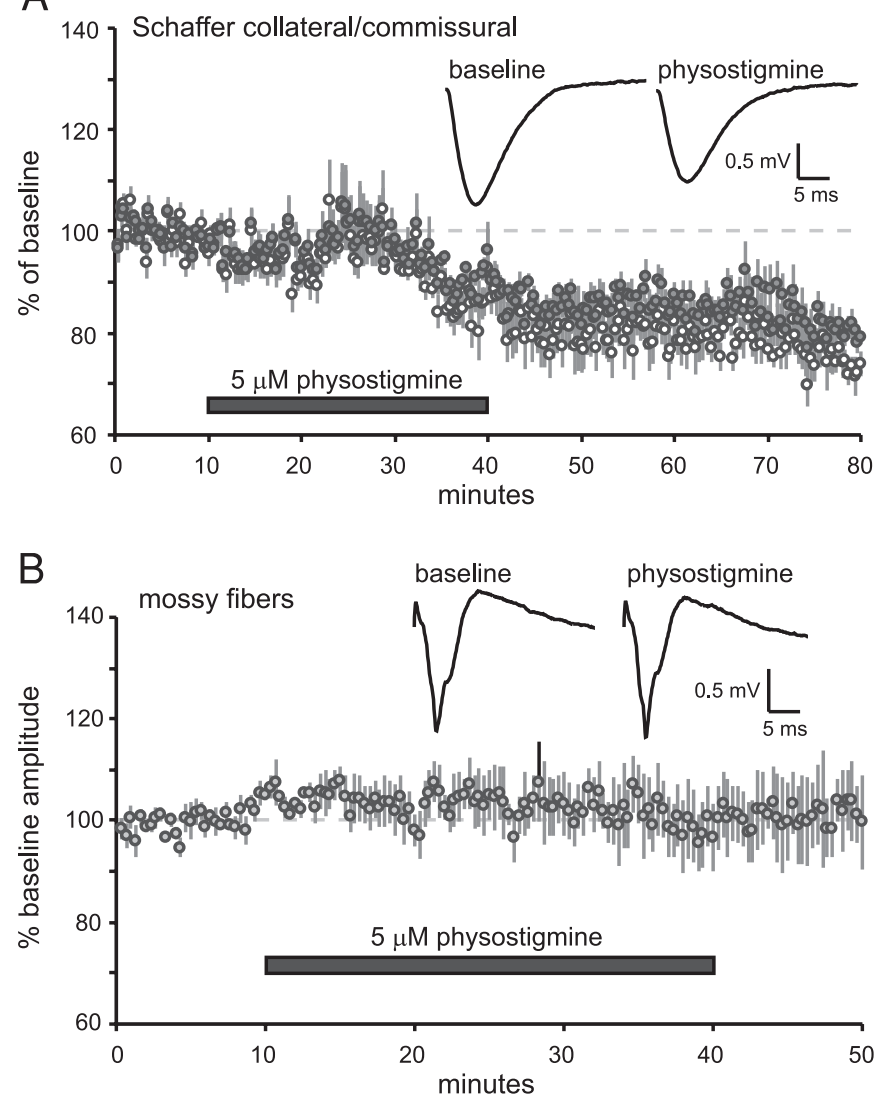

FIG. 2. Effects of physostigmine on excitatory pathways in the pyramidal cell fields. A: single stimulation pulses were delivered to the Schaffer collateral/commissural fibers in stratum radiatum of CA1. Physostigmine produced an approximately $20 \%$ decrease in slope and amplitude $(n=4)$. Representative traces for baseline and drug infusion periods are shown (inset). B: responses evoked by mossy fiber stimulation and recorded in stratum lucidum of CA3 were not significantly altered by physostigmine infusion $(n=4)$. Typical responses are shown for baseline and physostigmine infusion periods (inset).

decreases that were comparable to those obtained with physostigmine alone $(20 \pm 9 \%$ amplitude decrease for DMSO slices at the end of a 30-min physostigmine infusion, $n=3$ ). To ensure that the lack of a physostigmine effect was not related to reported interactions between CB1 activation and $\mathrm{GABA}_{\mathrm{A}}$ receptor-mediated inhibition (e.g., Hoffman and Lupica 2000), the experiments with AM251 were repeated in the presence of the $\mathrm{GABA}_{\mathrm{A}}$ antagonist PTX. As shown in Fig. $6 C$, incubation of slices with PTX did not affect the ability of AM251 to block physostigmine-induced depression of medial perforant path responses.

Combined immunocytochemistry and electron microscopy studies have found $\mathrm{m} 2$ type muscarinic receptors in a minority of axon terminals in the middle molecular layer of the dentate gyrus (Rouse et al. 1998). To test if physostigmine's effects at the medial perforant path synapse are mediated by $\mathrm{m} 2$ receptors, slices were treated with the selective antagonist, methoctramine. As shown in Fig. $6 D$, methoctramine did not prevent the physostigmine-induced reduction of the medial perforant path response. In control slices treated with methoctramine alone, the drug produced small and insignificant increases in medial perforant path responses.

\section{I S C U S S I O N}

The above results suggest that the cholinergic projections from septum to hippocampus reduce release from glutamatergic terminals and thereby depress fast excitatory transmission. Low to moderate concentrations of physostigmine caused a rapid reduction in perforant path responses and an increase in paired-pulse facilitation. The latter effect constitutes strong evidence for depressed release and suggests that this effect accounts for the synaptic depression produced by physostigmine. In agreement with this, the AChE inhibitor caused no evident postsynaptic changes. That the drug's actions on glutamatergic synapses were due to enhanced transmission at septo-dentate synapses was confirmed by showing that the effects of physostigmine were absent in slices in which the septal afferents had been previously eliminated.

Whether the cholinergic septal projections depress hippocampal synapses in vivo remains to be determined. Electrical stimulation of the medial septum is reported to increase population spikes but not the fEPSPs generated in dentate gyrus by the perforant path (Bilkey and Goddard 1985; Fantie and Goddard 1982; Mizumori et al. 1989). However, stimulation of the medial septum with glutamate, a manipulation less likely to activate fibers of passage than electrical pulses, is described as causing a brief and modest enhancement of perforant path EPSPs (Carre and Harley 2000). It is difficult to determine from these studies whether the predominant effect of the stimulus is on cholinergic projections into the hippocampus. Immunocytochemical mapping studies suggest that about $40 \%$ of the medial septal projection neurons are cholinergic (Amaral and Kurz 1985; Senut et al. 1989) and about 30\% are GABAergic (Kiss et al. 1990; Kohler et al. 1984); thus it is possible that effects of the type described here are generally masked in septal stimulation experiments in vivo. Surprisingly, there are very few results regarding the effects of physostigmine on perforant path responses in vivo, but one study does describe a suppressive effect (Vinogradova et al. 1996). Additional in vivo experiments using controls showing that the effects of AChE inhibitors are local (that is, on septo-hippocampal terminals) are needed to test if enhanced cholinergic transmission regulates excitatory synapses in vivo.

Analysis of the paired-pulse results provides some insight into the functional changes arising from cholinergic suppression of glutamatergic synapses. Specifically, responses to the second pulses in both the medial and lateral perforant paths were nearly equivalent in control and physostigmine-treated slices, indicating that paired-pulse facilitation offsets the lower probability of release caused by AChE inhibition. This suggests that enhanced cholinergic transmission will shift the responsivity of the hippocampus away from aperiodic inputs and toward afferent trains with inter-spike periods corresponding to the intervals appropriate for frequency facilitation. Two well-studied cortical rhythms (beta and gamma) satisfy this requirement, raising the possibility that cholinergic modulation alters hippocampal responsivity so as to favor inputs synchronized to either of these two firing patterns. It is noteworthy that cholinergic stimulation triggers beta and gamma oscillations in entorhino-hippocampal slices (Colgin et al. 2003; Fisahn et al. 1998; Shimono et al. 2000).

The effects of physostigmine were significantly larger for medial perforant path responses than for responses to other 


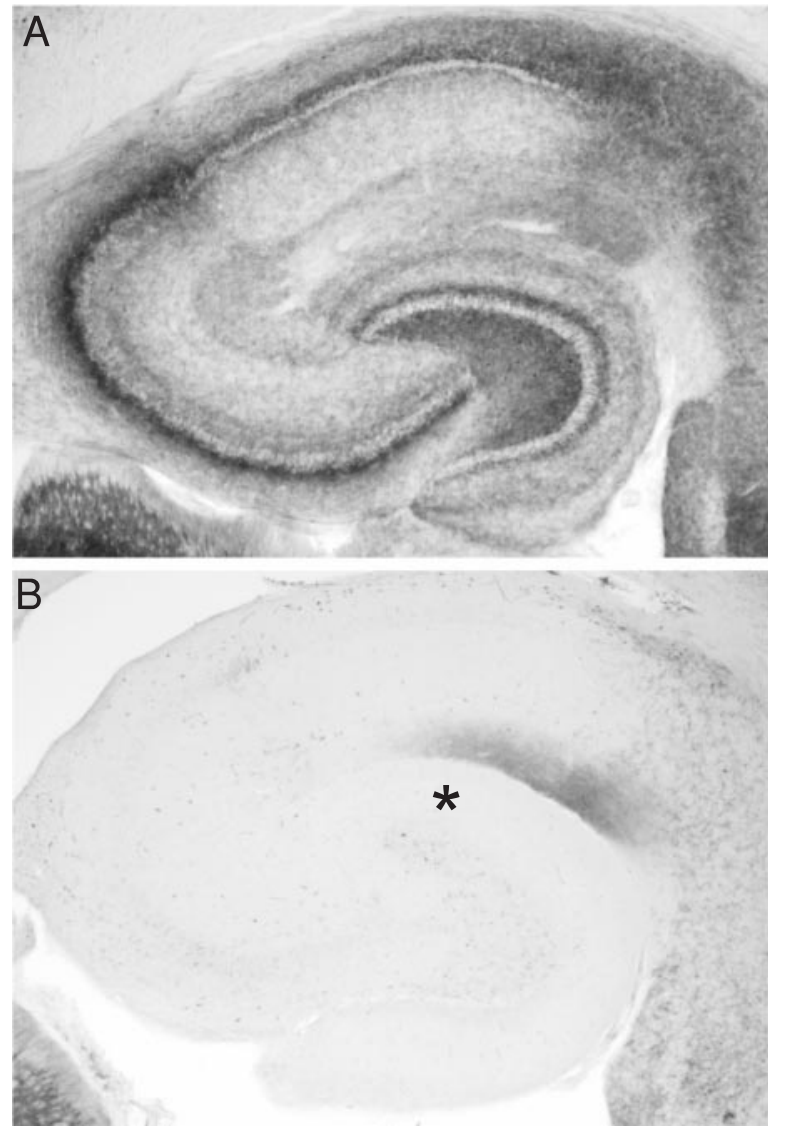

C

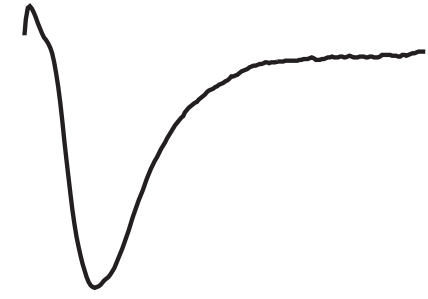

baseline

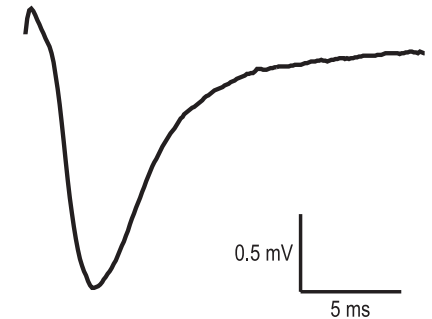

physostigmine

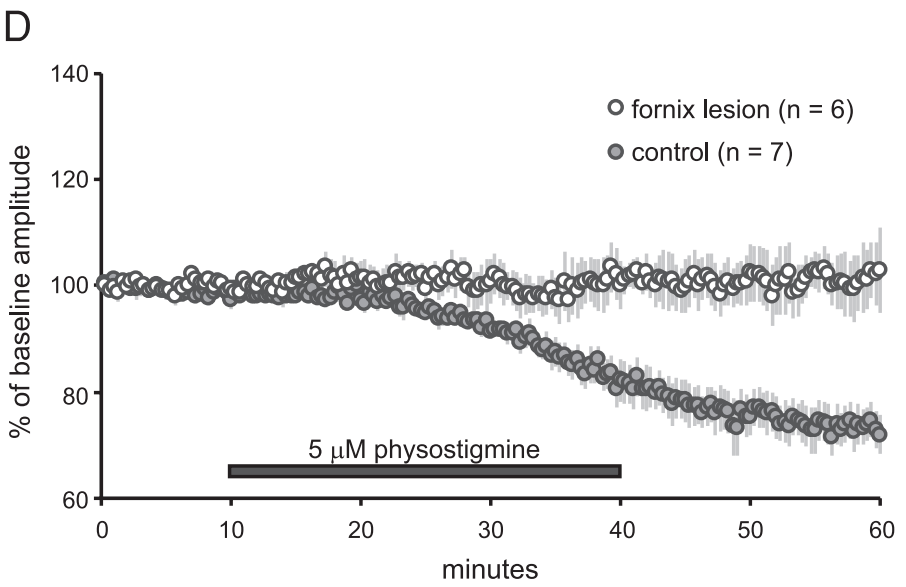

FIG. 3. Removal of septal afferents to hippocampus eliminates the effects of physostigmine on perforant path responses. The fimbria/fornix was ablated at the level of the hippocampal commissure 5-7 days prior to preparation of hippocampal slices. Sections processed for $\mathrm{AChE}$ histochemistry are shown for representative control $(A)$ and lesioned $(B)$ rats; note that there is no residual staining in the dentate molecular layer in the lesioned case $(B, *)$. Representative responses evoked by stimulation of the medial perforant path prior to and at the end of physostigmine infusion are shown in $C$. $D$ : summarized group data contrasting the magnitude of physostigmine-induced depression of medial perforant path responses in control slices with the complete lack of a physostigmine effect in slices cut from lesioned animals ( $n=7$ and 6 for control and lesion cases, respectively).

hippocampal projections. This could be related to the densities and distributions of cholinergic afferents across the different hippocampal subfields. As can be seen in Fig. 3 and described elsewhere (Lynch et al. 1977; Mosko et al. 1973; Storm-
Mathisen 1977), cholinergic afferents are more numerous in the middle molecular layer (the terminus of the medial perforant path) than in the more distal lateral perforant path zone, and significantly denser in these two lamina of stratum mo-

\section{A}

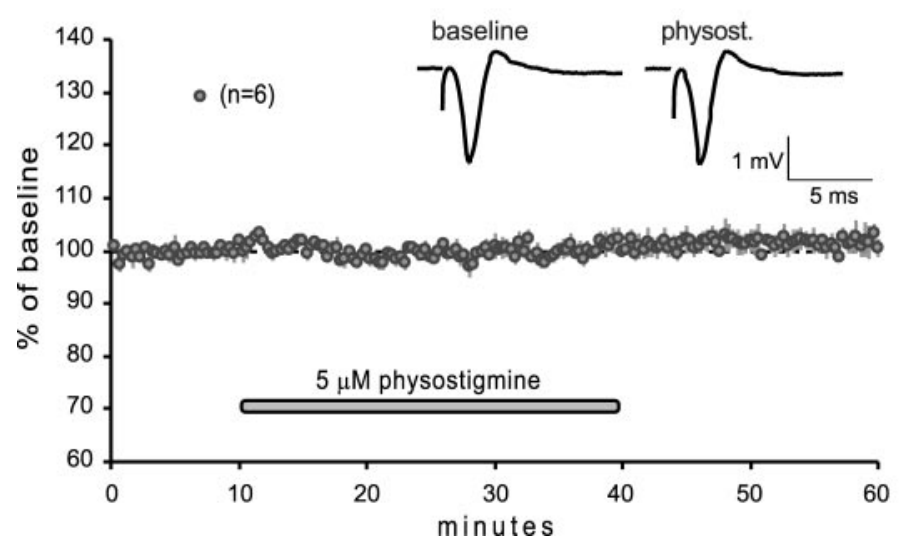

B

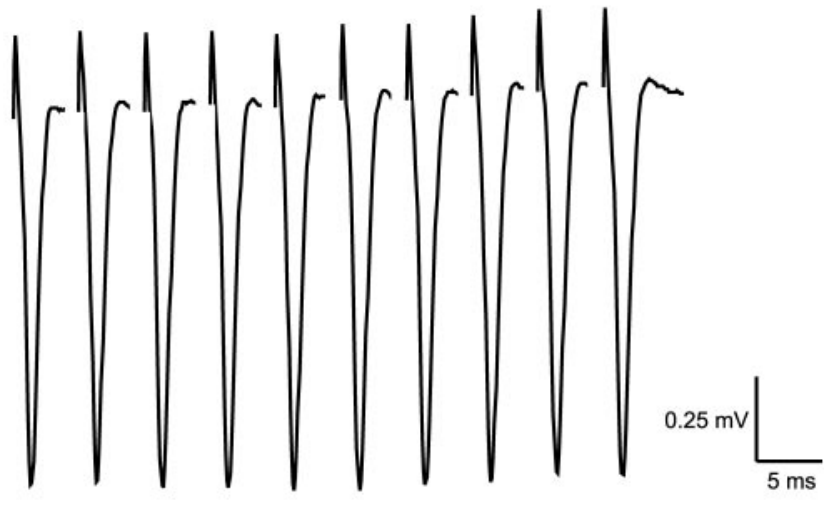

FIG. 4. Physostigmine does not affect measures of postsynaptic excitability. A: single stimulation pulses were delivered to the mossy fiber axons at a rate of 3 per minute and recordings collected from the inner leaf of granule cells. There was no detectable effect of physostigmine on the antidromic responses in a group of 6 slices. Representative traces are shown (inset). B: as expected for antidromic responses, these potentials did not exhibit paired-pulse facilitation or depression and were capable of following high-frequency $(200 \mathrm{~Hz})$ trains of stimulation. 
A

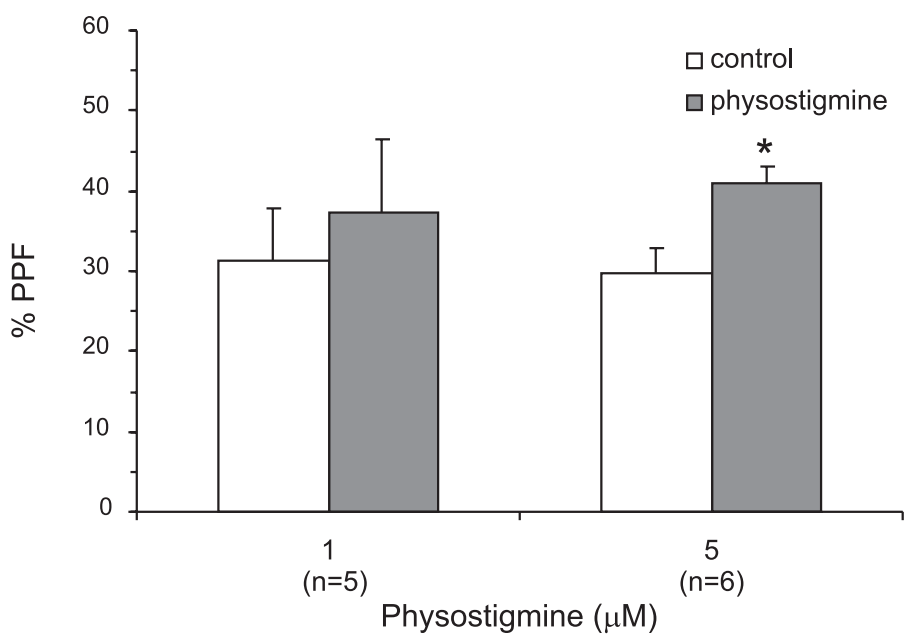

B

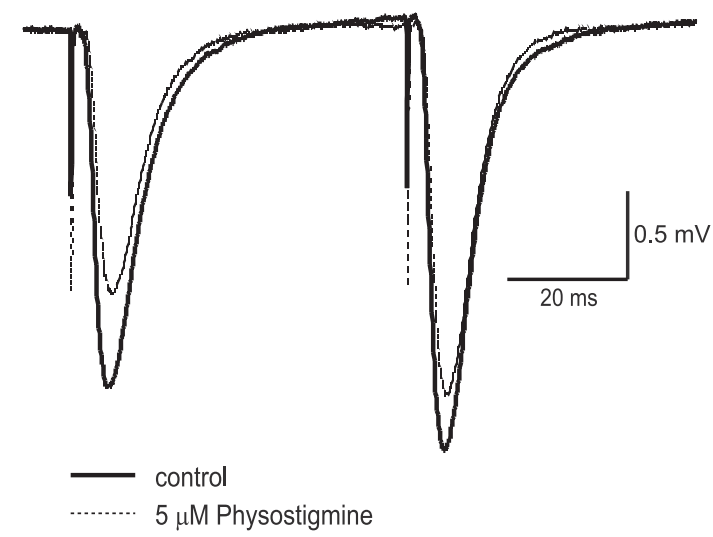

FIG. 5. Physostigmine increases paired-pulse facilitation in the lateral perforant path. As shown in $A$, at threshold concentration $(1 \mu \mathrm{M})$, physostigmine produced variable increases in the average paired-pulse facilitation of response amplitude in a group of 5 slices. At a slightly higher concentration $(5 \mu \mathrm{M})$, the effect was more reliable and achieved statistical significance $(n=6, P<$ 0.01). $B$ : responses to paired pulses, separated by $50 \mathrm{~ms}$, delivered to the lateral perforant path before and during $5 \mu \mathrm{M}$ physostigmine infusion. The drug (dotted trace) reduced the size of the field EPSP evoked by the first pulse but clearly left paired-pulse facilitation intact. Note that the 2 nd response in the presence of drug has nearly the same amplitude as the predrug 2nd response, indicating that paired-pulse facilitation is enhanced.

A

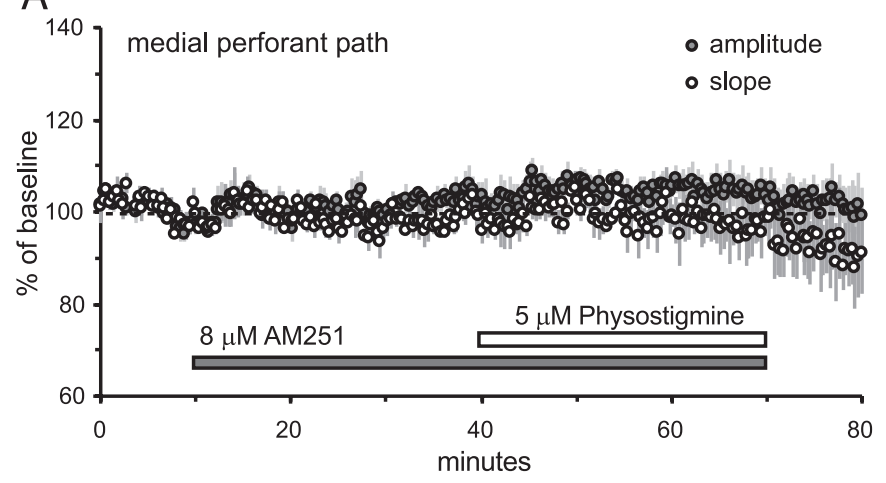

C

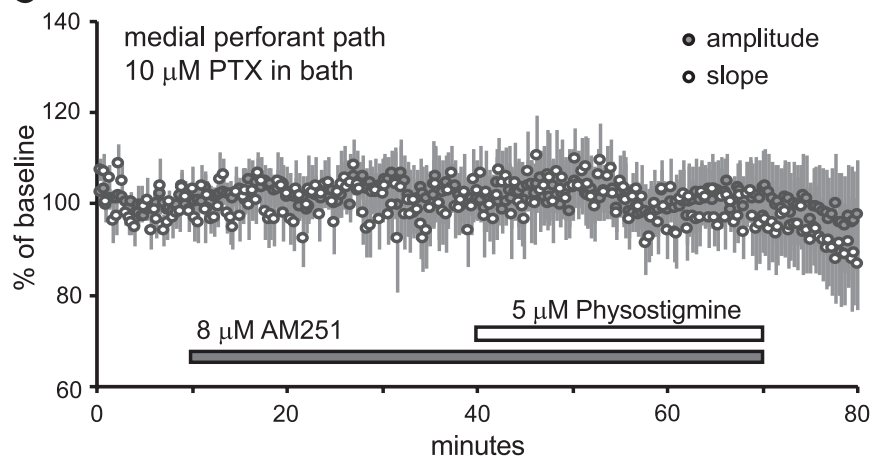

B
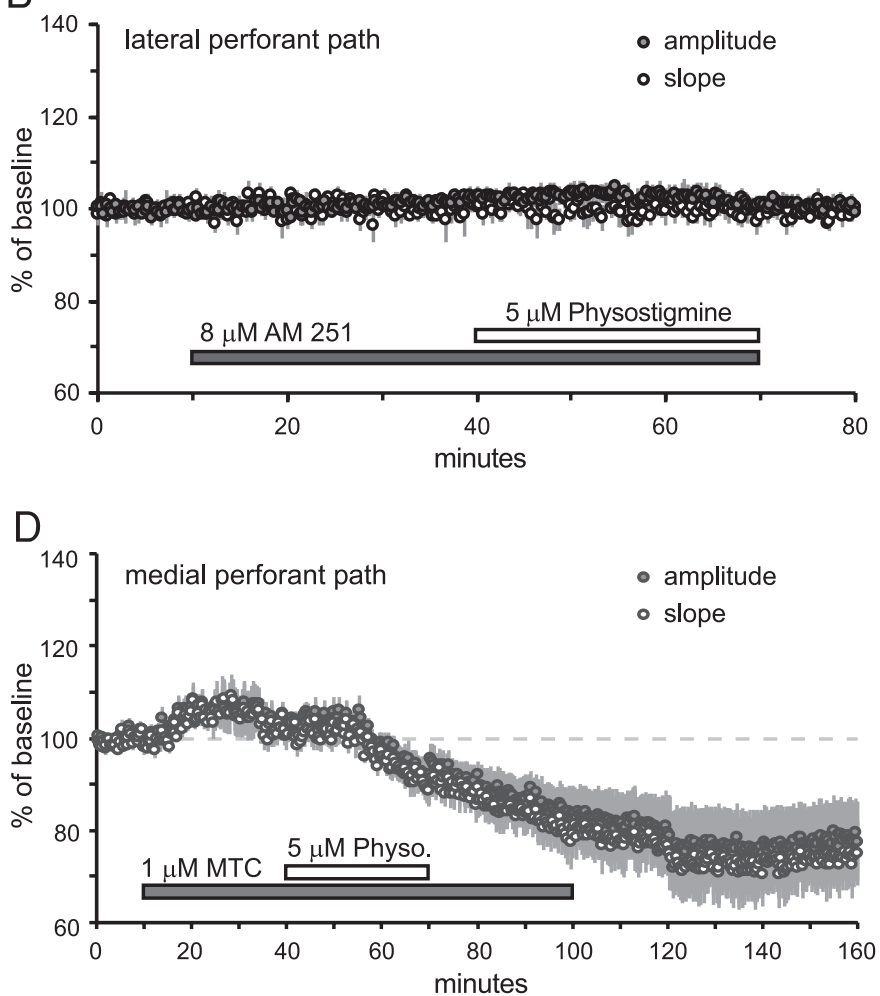

FIG. 6. Physostigmine-induced suppression of perforant path responses appears to be mediated by endocannabinoids and not presynaptic inhibition. $A$ and $B$ : CB1-selective antagonist AM251 was infused into slices $30 \mathrm{~min}$ prior to and throughout the 30-min infusion of physostigmine. Under these conditions, the latter drug had little or no effect on the size of the field EPSPs generated by stimulation of the medial $(n=4, A)$ or lateral $(n=6, B)$ perforant path. $C$ : AM251 maintained its ability to block physostigmine's effects on perforant path responses in slices $(n=7)$ incubated with the $\mathrm{GABA}_{\mathrm{A}}$ antagonist picrotoxin (PTX). $D$ : slices were infused with the $\mathrm{m} 2$-selective muscarinic antagonist methoctramine (MTC) for $30 \mathrm{~min}$ prior to physostigmine infusion, throughout physostigmine infusion, and for an additional $30 \mathrm{~min}$ after physostigmine washout $(n=5)$. Under these conditions, physostigmine produced decreases in perforant path responses that were not significantly different from decreases observed in the absence of MTC. 
leculare than in stratum radiatum of hippocampus proper. An additional possibility exists that the greater sensitivity of the medial perforant path to physostigmine relates to the peculiar paired-pulse depression effect exhibited by that pathway (McNaughton 1980). This could be tested by assessing the effects of physostigmine on slices of piriform cortex, where facilitation and depression are also found in adjacent pathways (Hasselmo and Bower 1990).

Physostigmine's depression of perforant path responses was blocked by atropine, indicating that the effect is mediated by muscarinic ACh receptors. There are at least four subtypes of muscarinic receptors $(\mathrm{m} 1-\mathrm{m} 4)$ found in the septal innervation zones of hippocampus (Levey et al. 1995). Two of these subtypes ( $\mathrm{m} 2$ and $\mathrm{m} 4$ ) have been localized to perforant pathway terminals, leading to the suggestion that cholinergic input from the septum could shut down glutamate release at the perforant path via a heteroreceptor mechanism (Rouse et al. 1998). However, electron microscopic analyses have failed to uncover evidence for axoaxonic synapses between septal and perforant path fibers in the molecular layer of the dentate gyrus (Clarke 1985; Cotman et al. 1973; Frotscher and Leranth 1985), and it is questionable whether diffusion of ACh from the sparsely scattered septal endings could significantly affect a far more numerous population of perforant path synapses. In this regard, it is important to note that the $\mathrm{m} 2$ antagonist tested in this study did not inhibit physostigmine-induced suppression of the medial perforant path response.

An alternative hypothesis is that endogenous cannabinoids act as retrograde messengers to mediate the effects of physostigmine on perforant path responses. Endocannabinoids, lipid-derived compounds that resemble the active agent in marijuana, are synthesized by neurons throughout the brain, including hippocampus (Di Marzo et al. 1998; Piomelli et al. 2000; Stella et al. 1997), and are responsible for the suppression of inhibitory postsynaptic currents (IPSCs) that occurs during depolarization of postsynaptic neurons (Ohno-Shosaku et al. 2001; Wilson and Nicoll 2001), an effect referred to as "depolarization induced suppression of inhibition" (DSI) (Llano et al. 1991; Pitler and Alger 1992b). Cholinergic stimulation enhances both DSI and endocannabinoid release within hippocampus, and these effects are largely blocked by AM251 and reduced in CB1 knockout mice (Kim et al. 2002). Previous in vitro work has shown that a cannabinoid agonist depresses the perforant path response, but this effect was not accompanied by an increase in paired-pulse facilitation (Kirby et al. 1995). However, a later study showed that the same cannabinoid agonist reduced EPSCs and enhanced paired-pulse facilitation in hippocampal slices (Misner and Sullivan 1999), and presynaptic inhibition of glutamatergic transmission by cannabinoid receptor activation has been demonstrated for hippocampal neurons using multiple agonists across a broad range of experimental conditions (Ameri et al. 1999; Hajos et al. 2001; Shen and Thayer 1999; Shen et al. 1996; Sullivan 1999). While cannabinoid receptor-mediated inhibition of glutamatergic transmission has been reported previously, the present results constitute the first evidence that the modulators may be used by cholinergic afferents to suppress excitatory transmission. The endocannabinoid effects described here are unusual in that they do not appear to involve postsynaptic depolarization, as evidenced by the absence of any changes in antidromic responses. Nonetheless, the above hypothesis is reasonable given the distribution of cannabinoid receptors in the perforant path termination zones. The molecular layer of the dentate gyrus has a high concentration of cannabinoid binding sites but expression of the appropriate mRNA is low in the granule cells. This pattern of results points to presynaptic localization of the receptors in the molecular layer (Mailleux and Vanderhaeghen 1992). In agreement with this, in situ hybridization analyses have shown that CB1, along with cholecystokinin $(\mathrm{CCK})$, is also expressed at low but significant levels by entorhinal layer II projection neurons that innervate the dentate gyrus (Marsicano and Lutz 1999).

In summary, facilitation of the cholinergic septo-hippocampal synapses causes a substantial depression of release from one of the major inputs to hippocampus (the medial perforant path) and lesser reductions in excitatory transmission at other sites within the structure. These effects appear to involve retrograde actions (postsynaptic to presynaptic) of cannabinoids. The results provide a new description of how septal projections alter operations within hippocampus, and coupled with the potent effects of cholinergic inputs on rhythm production (Gogolak et al. 1968; Petsche et al. 1962; Stewart and Fox 1989), suggest that their actions may serve to favor particular temporal patterns of input from cortex.

The authors thank A. Liu for assistance with AChE histochemistry and A. J. Collins and D. Ariniello for critically reading and commenting on an earlier draft of this manuscript.

\section{I S C L OS URES}

This work was supported by Matsushita Electric Industrial Co., Ltd., Grant MEI-27599 and by National Institute of Health Grants NS-37799 and AG00538. E. A. Kramár was supported by AG00096-18.

\section{REFERENCES}

Amaral DG and Kurz J. An analysis of the origins of the cholinergic and noncholinergic septal projections to the hippocampal formation of the rat. J Comp Neurol 240: 37-59, 1985.

Ameri A, Wilhelm A, and Simmet T. Effects of the endogeneous cannabinoid, anandamide, on neuronal activity in rat hippocampal slices. $\mathrm{Br} J$ Pharmacol 126: 1831-1839, 1999.

Behrends JC and ten Bruggencate G. Cholinergic modulation of synaptic inhibition in the guinea pig hippocampus in vitro: excitation of GABAergic interneurons and inhibition of GABA-release. J Neurophysiol 69: 626-629, 1993.

Benson DM, Blitzer RD, and Landau EM. An analysis of the depolarization produced in guinea-pig hippocampus by cholinergic receptor stimulation. J Physiol 404: 479-496, 1988.

Bilkey DK and Goddard GV. Medial septal facilitation of hippocampal granule cell activity is mediated by inhibition of inhibitory interneurones. Brain Res 361: 99-106, 1985.

Blackstad TW. On the termination of some afferents to the hippocampus and the fascia dentata. Acta Anat (Basel) 35: 202-214, 1958.

Broide RS, Robertson RT, and Leslie FM. Regulation of alpha7 nicotinic acetylcholine receptors in the developing rat somatosensory cortex by thalamocortical afferents. J Neurosci 16: 2956-2971, 1996.

Buzsaki G, Leung LW, and Vanderwolf CH. Cellular bases of hippocampal EEG in the behaving rat. Brain Res 287: 139-171, 1983.

Cajal S and Ramón Y. Histologie du Systeme Nerveux de l'Homme and des Vertebres. Madrid: Consejo Superior de Investigaciones Cientificas, 1955.

Carre GP and Harley CW. Glutamatergic activation of the medial septum complex: an enhancement of the dentate gyrus population spike and accompanying EEG and unit changes. Brain Res 861: 16-25, 2000.

Clarke DJ. Cholinergic innervation of the rat dentate gyrus: an immunocytochemical and electron microscopical study. Brain Res 360: 349-354, 1985.

Colgin LL, Kubota D, and Lynch G. Cholinergic plasticity in the hippocampus. Proc Natl Acad Sci USA 100: 2872-2877, 2003. 
Cotman CW, Matthews DA, Taylor D, and Lynch G. Synaptic rearrangement in the dentate gyrus: histochemical evidence of adjustments after lesions in immature and adult rats. Proc Natl Acad Sci USA 70: 3473-3477, 1973.

Di Marzo V, Melck D, Bisogno T, and De Petrocellis L. Endocannabinoids: endogenous cannabinoid receptor ligands with neuromodulatory action. Trends Neurosci 21: 521-528, 1998.

Fantie BD and Goddard GV. Septal modulation of the population spike in the fascia dentata produced by perforant path stimulation in the rat. Brain Res 252: 227-237, 1982

Fisahn A, Pike FG, Buhl EH, and Paulsen O. Cholinergic induction of network oscillations at $40 \mathrm{~Hz}$ in the hippocampus in vitro. Nature 394: 186-189, 1998.

Foster TC and Deadwyler SA. Acetylcholine modulates averaged sensory evoked responses and perforant path evoked field potentials in the rat dentate gyrus. Brain Res 587: 95-101, 1992.

Frotscher $\mathbf{M}$ and Leranth C. Cholinergic innervation of the rat hippocampus as revealed by choline acetyltransferase immunocytochemistry: a combined light and electron microscopic study. J Comp Neurol 239: 237-246, 1985.

Gerdeman $\mathbf{G}$ and Lovinger DM. CB1 cannabinoid receptor inhibits synaptic release of glutamate in rat dorsolateral striatum. J Neurophysiol 85: $468-$ 471, 2001.

Gogolak G, Stumpf C, Petsche H, and Sterc J. The firing pattern of septal neurons and the form of the hippocampal theta wave. Brain Res 7: 201-207, 1968.

Hajos N and Freund TF. Distinct cannabinoid sensitive receptors regulate hippocampal excitation and inhibition. Chem Phys Lipids 121: 73-82, 2002.

Hajos N, Ledent C, and Freund TF. Novel cannabinoid-sensitive receptor mediates inhibition of glutamatergic synaptic transmission in the hippocampus. Neuroscience 106: 1-4, 2001.

Hasselmo ME and Bower JM. Afferent and association fiber differences in short-term potentiation in piriform (olfactory) cortex of the rat. J Neurophysiol 64: 179-190, 1990.

Hasselmo ME and Fehlau BP. Differences in time course of ACh and GABA modulation of excitatory synaptic potentials in slices of rat hippocampus. J Neurophysiol 86: 1792-1802, 2001.

Hasselmo ME, Schnell E, and Barkai E. Dynamics of learning and recall at excitatory recurrent synapses and cholinergic modulation in rat hippocampal region CA3. J Neurosci 15: 5249-5262, 1995.

Hjorth-Simonsen A. Projection of the lateral part of the entorhinal area to the hippocampus and fascia dentata. J Comp Neurol 146: 219-232, 1972.

Hjorth-Simonsen A and Jeune B. Origin and termination of the hippocampal perforant path in the rat studied by silver impregnation. J Comp Neurol 144: 215-232, 1972.

Hoffman AF and Lupica CR. Mechanisms of cannabinoid inhibition of GABA(A) synaptic transmission in the hippocampus. J Neurosci 20: 2470 2479, 2000.

Kahle JS and Cotman CW. Carbachol depresses synaptic responses in the medial but not the lateral perforant path. Brain Res 482: 159-163, 1989.

Kim J, Isokawa M, Ledent $\mathbf{C}$, and Alger BE. Activation of muscarinic acetylcholine receptors enhances the release of endogenous cannabinoids in the hippocampus. J Neurosci 22: 10182-10191, 2002.

Kirby MT, Hampson RE, and Deadwyler SA. Cannabinoids selectively decrease paired-pulse facilitation of perforant path synaptic potentials in the dentate gyrus in vitro. Brain Res 688: 114-120, 1995.

Kiss J, Patel AJ, and Freund TF. Distribution of septohippocampal neurons containing parvalbumin or choline acetyltransferase in the rat brain. J Comp Neurol 298: 362-372, 1990.

Koelle GB and Friedenwald JS. A histochemical method for localizing cholinesterase activity. Proc Soc Exp Biol Med 70: 617-622, 1949.

Kohler C, Chan-Palay V, and Wu JY. Septal neurons containing glutamic acid decarboxylase immunoreactivity project to the hippocampal region in the rat brain. Anat Embryol (Berl) 169: 41-44, 1984.

Konopacki J, Maciver MB, Bland BH, and Roth SH. Theta in hippocampal slices: relation to synaptic responses of dentate neurons. Brain Res Bull 18: 25-27, 1987.

Kramis R, Vanderwolf $\mathbf{C H}$, and Bland BH. Two types of hippocampal rhythmical slow activity in both the rabbit and the rat: relations to behavior and effects of atropine, diethyl ether, urethane, and pentobarbital. Exp Neurol 49: 58-85, 1975.

Levey AI, Edmunds SM, Koliatsos V, Wiley RG, and Heilman CJ. Expression of $\mathrm{m} 1-\mathrm{m} 4$ muscarinic acetylcholine receptor proteins in rat hippocampus and regulation by cholinergic innervation. $J$ Neurosci 15: 40774092, 1995.
Lewis PR, Shute CC, and Silver A. Confirmation from choline acetylase analyses of a massive cholinergic innervation to the rat hippocampus. J Physiol 191: 215-224, 1967.

Llano I, Leresche N, and Marty A. Calcium entry increases the sensitivity of cerebellar Purkinje cells to applied GABA and decreases inhibitory synaptic currents. Neuron 6: 565-574, 1991.

Lynch G, Rose G, and Gall C. Anatomical and functional aspects of the septo-hippocampal projections. Ciba Found Symp 58: 5-24, 1977.

Madison DV, Lancaster B, and Nicoll RA. Voltage clamp analysis of cholinergic action in the hippocampus. J Neurosci 7: 733-741, 1987.

Maejima T, Ohno-Shosaku T, and Kano M. Endogenous cannabinoid as a retrograde messenger from depolarized postsynaptic neurons to presynaptic terminals. Neurosci Res 40: 205-210, 2001.

Mailleux $\mathbf{P}$ and Vanderhaeghen JJ. Distribution of neuronal cannabinoid receptor in the adult rat brain: a comparative receptor binding radioautography and in situ hybridization histochemistry. Neuroscience 48: 655-668, 1992

Marsicano G and Lutz B. Expression of the cannabinoid receptor CB1 in distinct neuronal subpopulations in the adult mouse forebrain. Eur J Neurosci 11: 4213-4225, 1999.

McNaughton BL. Evidence for two physiologically distinct perforant pathways to the fascia dentata. Brain Res 199: 1-19, 1980.

Mellgren SI and Srebro B. Changes in acetylcholinesterase and distribution of degenerating fibres in the hippocampal region after septal lesions in the rat. Brain Res 52: 19-36, 1973.

Misner DL and Sullivan JM. Mechanism of cannabinoid effects on long-term potentiation and depression in hippocampal CA1 neurons. J Neurosci 19: 6795-6805, 1999.

Mizumori SJ, McNaughton BL, and Barnes CA. A comparison of supramammillary and medial septal influences on hippocampal field potentials and single-unit activity. $J$ Neurophysiol 61: 15-31, 1989.

Mosko S, Lynch G, and Cotman CW. The distribution of septal projections to the hippocampus of the rat. J Comp Neurol 152: 163-174, 1973.

Nafstad PH. An electron microscope study on the termination of the perforant path fibres in the hippocampus and the fascia dentata. Z Zellforsch Mikrosk Anat 76: 532-542, 1967.

Nakajima Y, Nakajima S, Leonard RJ, and Yamaguchi K. Acetylcholine raises excitability by inhibiting the fast transient potassium current in cultured hippocampal neurons. Proc Natl Acad Sci USA 83: 3022-3026, 1986.

Ohno-Shosaku T, Maejima T, and Kano M. Endogenous cannabinoids mediate retrograde signals from depolarized postsynaptic neurons to presynaptic terminals. Neuron 29: 729-738, 2001.

Petsche H, Stumpf C, and Gogolak G. The significance of the rabbit's septum as a relay station between the midbrain and the hippocampus. I. The control of hippocampal arousal activity by the septum cells. Electroencephalogr Clin Neurophysiol 14: 202-211, 1962.

Piomelli D, Giuffrida A, Calignano A, and Rodriguez de Fonseca F. The endocannabinoid system as a target for therapeutic drugs. Trends Pharmacol Sci 21: 218-224, 2000.

Pitler TA and Alger BE. Cholinergic excitation of GABAergic interneurons in the rat hippocampal slice. J Physiol 450: 127-142, 1992a.

Pitler TA and Alger BE. Postsynaptic spike firing reduces synaptic GABAA responses in hippocampal pyramidal cells. J Neurosci 12: 4122-4132, 1992b.

Qian J and Saggau P. Presynaptic inhibition of synaptic transmission in the rat hippocampus by activation of muscarinic receptors: involvement of presynaptic calcium influx. Br J Pharmacol 122: 511-519, 1997.

Raisman G, Cowan WM, and Powell TPS. The extrinsic afferent, commissural, and associational fibres of the hippocampus. Brain 88: 963-996, 1965.

Rouse ST, Gilmor ML, and Levey AI. Differential presynaptic and postsynaptic expression of $\mathrm{m} 1-\mathrm{m} 4$ muscarinic acetylcholine receptors at the perforant pathway/granule cell synapse. Neuroscience 86: 221-232, 1998.

Senut MC, Menetrey D, and Lamour Y. Cholinergic and peptidergic projections from the medial septum and the nucleus of the diagonal band of Broca to dorsal hippocampus, cingulate cortex and olfactory bulb: a combined wheatgerm agglutinin- apohorseradish peroxidase-gold immunohistochemical study. Neuroscience 30: 385-403, 1989.

Shen M, Piser TM, Seybold VS, and Thayer SA. Cannabinoid receptor agonists inhibit glutamatergic synaptic transmission in rat hippocampal cultures. J Neurosci 16: 4322-4334, 1996.

Shen $\mathbf{M}$ and Thayer SA. Delta9-tetrahydrocannabinol acts as a partial agonist to modulate glutamatergic synaptic transmission between rat hippocampal neurons in culture. Mol Pharmacol 55: 8-13, 1999. 
Shimono K, Brucher F, Granger R, Lynch G, and Taketani M. Origins and distribution of cholinergically induced beta rhythms in hippocampal slices. J Neurosci 20: 8462-8473, 2000.

Stella N, Schweitzer P, and Piomelli D. A second endogenous cannabinoid that modulates long-term potentiation. Nature 388: 773-778, 1997.

Stewart $\mathbf{M}$ and Fox SE. Firing relations of medial septal neurons to the hippocampal theta rhythm in urethane anesthetized rats. Exp Brain Res 77: 507-516, 1989.

Storm-Mathisen J. Localization of putative transmitters in the hippocampal formation: with a note on the connections to septum and hypothalamus. Ciba Found Symp 58: 49-86, 1977.

Sullivan JM. Mechanisms of cannabinoid-receptor-mediated inhibition of synaptic transmission in cultured hippocampal pyramidal neurons. J Neurophysiol 82: 1286-1294, 1999.
Valentino RJ and Dingledine R. Presynaptic inhibitory effect of acetylcholine in the hippocampus. J Neurosci 1: 784-792, 1981.

Vinogradova OS, Brazhnik ES, Stafekhina VS, and Kichigina VF. Modulation of the influences of cortical input on hippocampal neurons by cholinergic substances. Neurosci Behav Physiol 26: 45-54, 1996.

Vogt KE and Regehr WG. Cholinergic modulation of excitatory synaptic transmission in the CA3 area of the hippocampus. Neuroscience 21: 75-83, 2001.

Wilson RI and Nicoll RA. Endogenous cannabinoids mediate retrograde signalling at hippocampal synapses. Nature 410: 588-592, 2001.

Yamamoto $\mathbf{C}$ and Kawai N. Presynaptic action of acetylcholine in thin sections from the guinea pig dentate gyrus in vitro. Exp Neurol 19: 176-187, 1967. 